\title{
A phase I/II trial of irinotecan-cisplatin combined with an anti-late- diarrhoeal programme to evaluate the safety and antitumour response of this combination therapy in patients with advanced non-small-cell lung cancer
}

\author{
Y Takeda*,', E Tsuduki', S Izumi', M Hojo', M Kamimura', G Naka', K Kobayashi ${ }^{2}$ and K Kudo' \\ 'Department of Respiratory Medicine, International Medical Center of Japan, 1-21-I Toyama Shinjuku-ku, Tokyo 162-8655, Japan; ${ }^{2}$ Department of \\ Respiratory Medicine, Saitama Cancer Center, Komuro, Ina 362-0806, Saitama, Japan
}

\begin{abstract}
We conducted a phase I/II study in patients with advanced non-small-cell lung cancer (NSCLC) to increase the therapeutic index of the cisplatin-irinotecan combination by institution of an anti-late-diarrhoeal program (ADP). A total of 77 chemotherapy-naive patients with advanced NSCLC were enrolled. The cisplatin dose was fixed at $60 \mathrm{mg} \mathrm{m}^{-2}$ (Day I). Irinotecan was escalated in $5 \mathrm{mg} \mathrm{m}^{-2}$ increments, starting from $60 \mathrm{mg} \mathrm{m}^{-2}$ (Days I and 8). ADP consisted of oral sodium bicarbonate, magnesium oxide, basic water, and ursodeoxycholic acid, and was administered orally for 4 days with each dose of irinotecan. In the phase I portion, irinotecan pharmacokinetics was also examined. After the recommended dose of irinotecan with ADP was determined, a phase II study was conducted to evaluate the response. Maximum tolerated dose was reached at an irinotecan dose of $80 \mathrm{mg} \mathrm{m}^{-2}$ (Grade 4 diarrhoea and neutropenia). Pharmacokinetic studies show that the maximum concentration and the area under the curve of both irinotecan and SN38 (active metabolite of irinotecan) tend to increase in the dose-dependent manner of irinotecan. The phase II portion of the study included 48 patients, who were treated with $75 \mathrm{mg} \mathrm{m}^{-2}$ of irinotecan. Grade 3/4 toxicities included neutropenia in $65 \%$, leucopenia in 33\%, and late diarrhoea in $6 \%$ of the patients. During this treatment, PS did not change in $65 \%$ of patients. At the end of the chemotherapy, PS did not decline in $90 \%$ of patients. In the phase II portion, a response occurred in $63 \%$ (95\% confidential interval $(\mathrm{Cl}), 47-76 \%)$ of patients. Median time to progression was 19 weeks (95\% Cl, I5-22 weeks), and median survival was 52 weeks ( $95 \%$ Cl, 39-64 weeks). This regimen of irinotecan and cisplatin with ADP resulted in promising efficacy with acceptable toxicity for patients with advanced NSCLC. This regimen is a candidate for the experimental arm towards future phase III studies.
\end{abstract}

British Journal of Cancer (2005) 93, I34I-1349. doi:I0.1038/sj.bjc.6602866 www.bjcancer.com

Published online 15 November 2005

(c) 2005 Cancer Research UK

Keywords: irinotecan; anti-late-diarrhoeal program; cisplatin; non-small-cell lung cancer

Lung cancer is a major health-care problem worldwide. Patients with advanced non-small-cell lung cancer (NSCLC) have a poor prognosis because this disease is incurable with currently available treatments. Platinum-based two drug combinations improve survival as well as the quality of life for patients with advanced NSCLC (Non-small Cell Lung Cancer Collaborative Group, 1995). However, an efficacy plateau has been reached with the currently available two-drug combinations in the treatment of advanced NSCLC (Schiller et al, 2002). Clinical trials are ongoing to investigate novel combination chemotherapies to improve the outcome for advanced NSCLC.

Irinotecan, a semisynthetic derivative of the plant alkaloid camptothecin, exhibits antitumour activity by inhibiting topo-

*Correspondence: Dr Y Takeda; E-mail: ytakeda@imcj.hosp.go.jp Received II August 2005; revised 12 October 2005; accepted 17 October 2005; published online I5 November 2005 isomerase I. Irinotecan has been approved for anticancer therapy in the United States, Europe, and Japan (Garcia-Carbonero and Supko, 2002). However, irinotecan is associated with toxicities, including severe late diarrhoea and leucopenia (Fukuoka et al, 1992; Kobayashi et al, 1998). Some studies have documented success with high-dose loperamide for treating irinotecan-associated late diarrhoea (Bleiberg and Cvitkovic, 1996; Merrouche et al, 1997). However, there is still no effective strategy for preventing this dose-limiting adverse effect. Grade 3/4 late diarrhoea occurs in $20-30 \%$ of patients treated with irinotecan at the recommended doses (Fukuoka et al, 1992; Conti et al, 1996; Saltz et al, 2000). Therefore, strategies to prevent late diarrhoea should allow for more effective use of this drug.

Alkaline conditions within the intestinal lumen decrease reabsorption of irinotecan and its metabolites (Kobayashi et al, 1999; Ikegami et al, 2002). The rationale was to prevent absorption by oral alkalisation $(\mathrm{OA})$, which should in turn reduce epithelial damage and its impact on subsequent late diarrhoea. Controlling 
defecation (CD) should prevent constipation, thereby also preventing epithelial disruption and allowing less time for additional absorption. Based on these concepts, we conducted a case-control study to evaluate the ability of OA and CD treatment to prevent irinotecan-induced side effects (Takeda et al, 2001). A multivariate analysis showed that $\mathrm{OA}$ and $\mathrm{CD}$ treatment reduced the incidence of side effects such as late diarrhoea, emesis, and leucopenia. Hence, we hypothesised that OA and CD could be used as an anti-late-diarrhoeal programme (ADP) with irinotecan therapy. We designed a novel regimen to increase the therapeutic index of the cisplatin-irinotecan combination by decreasing the toxicities of irinotecan and instituting ADP. The main objectives of this study were to determine the maximum tolerated dose of irinotecan and cisplatin with the use of ADP in the phase I portion of the study and to evaluate the response rate of irinotecan and cisplatin with ADP in chemotherapy-naive advanced NSCLC patients in the phase II portion of the study.

\section{PATIENTS AND METHODS}

\section{Patients}

All patients had histologically or cytologically confirmed NSCLC. Eligibility criteria included: (1) surgically unresectable, stage III or IV disease; (2) no prior chemotherapy; (3) age 20-75 years; (4) performance status (PS) $\leqslant 2$ on the Eastern Cooperative Oncology Group (ECOG) scale; (5) adequate bone marrow function (leucocyte count $>4000 \mu \mathrm{l}^{-1}$; platelet count $>100000 \mu \mathrm{l}^{-1}$; haemoglobin concentration $>9 \mathrm{~g} \mathrm{dl}^{-1}$ ), hepatic function (bilirubin $<1.5 \mathrm{mg} \mathrm{ml}^{-1}$; transaminases $<2 \times$ upper limit of normal), and renal function (creatinine $<1.5 \mathrm{mg} \mathrm{dl}^{-1}$ and creatinine clearance $>60 \mathrm{ml} \mathrm{min}^{-1}$ ); (6) life expectancy of 8 weeks or longer; (7) written informed consent; and (8) The presence of measurable disease was necessary in patients with only stage IIIB or IV disease who were enrolled in the phase II portion of the study.

Exclusion criteria were: (1) massive pleural effusion or cardiac effusion (cardiac tamponade); (2) symptomatic brain metastases; (3) prior surgery within 4 weeks; (4) uncontrolled comorbid diseases such as angina pectoris, cardiac infarction within 3 months, cardiac failure, uncontrolled hypertension, uncontrolled diabetes mellitus, active infectious diseases, ileus, interstitial pneumonitis, or lung fibrosis; (5) concurrent malignancies; (6) pregnancy or lactation; (7) inability to consume sodium and water as required by ADP regimen. This protocol was approved by the Institutional Review Board of the International Medical Center of Japan.

\section{Treatment}

All patients were treated with combined chemotherapy consisting of cisplatin and irinotecan delivered every 3 weeks. Cisplatin $\left(60 \mathrm{mg} \mathrm{m}^{-2}\right)$ was administered intravenously on Day 1 after adequate hydration. On Days 1 and 8, irinotecan was given in $500 \mathrm{ml}$ of normal saline as a $90 \mathrm{~min}$ intravenously (i.v.) infusion. All patients received the same antiemetic regimen, which consisted of metoclopramide $\left(10-20 \mathrm{mg} \mathrm{day}^{-1}\right.$ for 4 days), corticosteroid (4-5 $\mathrm{mg} \mathrm{day}^{-1}$ betamethasone for 3 days), and 5-hydroxytryptamine (5-HT3) receptor antagonist $\left(1 \mathrm{mg} \mathrm{day}^{-1}\right.$ granisetron for 2 days) given prophylactically by i.v. infusion before and after the administration of chemotherapy. After that, oral administration of 5-HT3 antagonists ( $4 \mathrm{mg} \mathrm{day}^{-1}$ ondansetron) was continued for 4 days. The dose of irinotecan was withheld for leucopenia $\left(<3000 \mu \mathrm{l}^{-1}\right)$ and/or diarrhoea $>$ Grade 1. Granulocyte-colonystimulating factor (G-CSF) was administered when Grade 3 leucopenia $\left(<2000 \mu \mathrm{l}^{-1}\right)$ and/or granulocytopenia $\left(<1000 \mu \mathrm{l}^{-1}\right)$ were observed. Before the next cycle was started, the leucocyte and platelet counts had to be $\geqslant 3000$ and $100000 \mu \mathrm{l}^{-1}$, respectively. If more than 6 weeks passed from the time of the last treatment before these criteria were satisfied, the patient was removed from the study.

The rationale for the ADP used in this study has been reported in more detail elsewhere (Takeda et al, 2001). In brief, ADP was started in the morning on Day 1 before irinotecan and cisplatin administration and continued for 4 days. ADP consisted of sodium bicarbonate, magnesium oxide, basic water, and ursodeoxycholic acid (UDCA) administered orally. The former three agents have a basic $\mathrm{pH}$ and directly mediate alkalisation from the duodenal lumen. Ursodeoxycholic acid has been reported to stimulate bile flow associated with a bicarbonate-rich choleresis and to increase biliary pH (Strazzabosco et al, 1991). Magnesium oxide demonstrates a laxative action, which was intended to shorten the dwelling time of irinotecan and its metabolites within the intestine. For OA, patients were given sodium bicarbonate $0.5 \mathrm{~g}$ orally and magnesium oxide $0.5 \mathrm{~g}$ orally after every meal and before sleep, for a total of four doses per day. Patients also took UDCA $100 \mathrm{mg}$ orally after every meal, for a total of three doses per day, and basic water $(\mathrm{pH}>7.2)$ for a total of $1500-2000 \mathrm{ml}$ per day. Additional magnesium oxide and basic water were also given to patients to control defecation, with a goal of two bowel movements per day (CD). If patients developed watery diarrhoea during ADP, magnesium oxide administration was stopped. If diarrhoea occurred on the day when irinotecan was administered, anticholinergic drugs were used for treatment (Gandia et al, 1993). Late diarrhoea, which occurred more than 6 days after each dose of irinotecan administration, was treated with a high dose of loperamide as described by Bleiberg et al (Bleiberg and Cvitkovic, 1996). Since irinotecan was administered on Days 1 and 8, we defined late diarrhoea as occurring more than 6 days after irinotecan administration and not explained by ADP-induced early diarrhoea. ADP-induced early diarrhoea was defined by checking the $\mathrm{pH}$ of the stool. If diarrhoea $\mathrm{pH}$ was alkaline during the period of ADP, diarrhoea was thought to be from ADP (Takeda et al, 2001). If high-dose loperamide therapy did not stop late diarrhoea altogether or if late diarrhoea of $\geqslant$ Grade 3 appeared, the patient was given fluid by intravenous hyperalimentation (IVH).

\section{Study design}

The doses of irinotecan were escalated in $5 \mathrm{mg}$ increments from $60 \mathrm{mg} \mathrm{m}^{-2}$, using three to six patient cohorts (Table 2). The first dose level was $60 \mathrm{mg} \mathrm{m}^{-2}$ of irinotecan on Days 1 and 8 with no ADP $(60 \mathrm{~N})$. For the second level (60P) and beyond, patients were treated with ADP. The maximum tolerated dose (MTD) was defined as the dose at which dose-limiting toxicities (DLTs) occurred in one-third, or more, of the patients. DLT was defined as: (1) ECOG common toxicity criteria (CTC) Grade 4 leucopenia or Grade 4 neutropenia lasting more than 5 days; (2) Grade 4 leucopenia or Grade 4 neutropenia with fever more than $38^{\circ} \mathrm{C}$; (3) Grade 4 thrombocytopenia; (4) Grade 3 or 4 nonhaematological toxicity (except for alopecia, nausea and vomiting, or constipation) lasting more than 5 days; (5) Grade 2 diarrhoea lasting more than 7 days; or (6) Grade 3/4 diarrhoea. Once the MTD and the recommended dose were defined, patients were accrued to the phase II portion of the study. The primary end point of this phase II study was response rate and secondary end points included time to progression (TTP), survival and determination of toxicities.

\section{Evaluation}

Pretreatment evaluation included: PS, chest radiograph, bone scintiscan, computed tomography of the head, chest, and abdomen, and fiberoptic bronchoscopy. Prior to each chemotherapy cycle, patients were subjected to a complete blood cell count (CBC) that included a differential count, serum chemistry for renal and hepatic functions, electrolyte analysis, urinalysis, and PS. complete 
blood cell count, serum chemistry, electrolyte analysis, urinalysis, chest radiographs, and PS were assessed at least once a week after the initial evaluation. PS was also checked at the end of each chemotherapy cycle. During the cycle of chemotherapy, the $\mathrm{pH}$ of diarrhoea was examined using a $\mathrm{pH}$ meter, HM-14P (TOA Electronics Ltd, Tokyo, Japan) (Takeda et al, 2001) or $\mathrm{pH}$ test sheet (Universal test paper or Brom-Thymol-Blue test paper; Advantec, Toyo Roshi Kaisha Ltd, Tokyo, Japan). Tumour response was classified in accordance with World Health Organization criteria (World Health Organization, 1979). ECOGCTC was used to Grade toxicity. Duration for toxicities, measured in this study, refers to the time required for recovery to toxicity $\leqslant$ Grade 1. The adherence of ADP was the average of the compliance of water intake and drug intake. The compliance of water intake was defined as: (total amount of water consumed)/ (amount of water intake prescribed). The compliance of drug intake was calculated as the percentage of compliance with medicines that were to be taken as scheduled for 3 days. Analysis was conducted on an intent to treat for toxicity and efficacy profile. Subtraction PS was to subtract the PS at certain time points of chemotherapy from the PS at the start of chemotherapy. The minus value of subtraction PS indicates declined PS. The plus value indicates improved PS. Analyses on the follow-up data were performed when more than two-thirds of the patients were dead or 12 months had passed since the enrollment of the last patients. Time to progression was defined as the time from the date of entry to the date of progressive disease, the last follow-up, or death without progression. The duration of survival was determined as the number of weeks from the date of entry to death or the last follow-up.

\section{Pharmacokinetics}

Blood samples $(5 \mathrm{ml})$ were obtained from the arm opposite the one used for chemotherapy infusion before the irinotecan infusion, at the end of infusion, and 1, 2, 4, 8, 24, 48, $72 \mathrm{~h}$ after completion of the infusion. Serial plasma samples were acquired on the first cycle from the patients. Sample collection started in each patient when irinotecan was administered on Day 1 . The blood was centrifuged immediately, and the plasma obtained was stored at $-80^{\circ} \mathrm{C}$ until analysis. Total plasma concentration of irinotecan, SN-38 (active metabolite of irinotecan, 7-ethyl-10-hydroxycamptothecin), and SN38 glucuronide (SN-38G) were measured using the highperformance liquid chromatography method previously described (Kurita and Kaneda, 1999). Maximum plasma concentrations (Cmax, $\left.\mu \mathrm{g} \mathrm{ml}^{-1}\right)$, elimination half-life $\left(T_{1 / 2}\right.$, hours), areas under the plasma-concentration time curve $\left(\mathrm{AUC}_{0-\infty}, \mu \mathrm{gh}^{-1} \mathrm{ml}^{-1}\right)$, and mean resident time (MRT, hours) of each compound were determined by noncompartment analysis using the computer program, WinNonLin Professional version 4.1 (Pharsight Corporation, Mountain View, CA, USA).

\section{Statistical analysis}

We chose a target response probability for the regimen of $60 \%$ and lowest response rate of interest to be $40 \%$. According to the Simon two-stage optimal design, a total of 46 patients were required to test this hypothesis in the phase II portion. At least seven major responses had to be observed in the first 16 assessable patients to continue enrollment to the 2 nd stage of the study (with type 1 and 2 errors of 0.05 and 0.20 , respectively) (Simon, 1989). Patients not assessable for response (because of treatment refusal or early treatment discontinuation for any reasons other than progression) were considered as nonresponders in calculation of the objective response rate. We also calculated the $95 \%$ exact confidential intervals (CIs) for response rate. Patients who received at least one cycle of chemotherapy were considered evaluable for response. Overall survival curves were estimated by the Kaplan-Meier method (Kaplan and Meier, 1958). According to the report by Schemper and Smith, median follow-up was estimated by reverse Kaplan-Meier method (Schemper and Smith, 1996). All analyses were performed using the Statistical Package for Social Sciences (SPSS) for Windows 10.0J.

\section{RESULTS}

\section{Patients}

Between June 1997 and August 2002, 77 patients were enrolled at the International Medical Center of Japan. In the phase I portion of the study, all patients were evaluable for toxicities. In the phase II portion, 48 patients were enrolled, and all were evaluable for toxicity. In all, 71 patients had either stage IIIB or IV disease. Six had stage IIIA disease. Patients' characteristics are summarised in Table 1 .

In all, 21 patients were women, and the median age of all patients was 64 years (range, $36-75$ years). Of patients, $93 \%$ had a PS of 0 or 1 . Three patients had undergone prior surgical resection (palliative surgery). One patient had received prior palliative irradiation therapy to brain metastasis.

\section{DLTs and MTD}

In all, 29 patients received 61 cycles of chemotherapy in the phase I portion of the study (mean 2, range 1-4) (Table 2). There were no treatment-related deaths. Two of seven (29\%) patients enrolled in dose level $60 \mathrm{~N}$ experienced Grade 4 neutropenia lasting 6 and 7 days, respectively. In that the objective of this portion of the study was to determine the MTD for the combination with the use of ADP, dose escalation continued. There were no DLTs in patients treated in cohorts $60 \mathrm{P}$ and $65 \mathrm{P}$. At $70 \mathrm{P}$, only one of four patients

Table I Patients' characteristics

\begin{tabular}{|c|c|c|c|}
\hline \multirow[b]{2}{*}{ Characteristics } & \multicolumn{2}{|c|}{ Phase } & \multirow[b]{2}{*}{ Total } \\
\hline & I & II & \\
\hline \multicolumn{4}{|l|}{$\operatorname{Sex}(n)$} \\
\hline Male & 21 & 35 & 56 \\
\hline Female & 8 & 13 & 21 \\
\hline \multicolumn{4}{|l|}{ Age (years) } \\
\hline Median & 66 & 62 & 64 \\
\hline Range & $36-73$ & $36-75$ & $36-75$ \\
\hline \multicolumn{4}{|l|}{ ECOG PS (n) } \\
\hline 0 & 10 & 10 & 20 \\
\hline I & 16 & 36 & 52 \\
\hline 2 & 3 & 2 & 5 \\
\hline \multicolumn{4}{|l|}{ Histology (n) } \\
\hline Adenocarcinoma & 25 & 35 & 60 \\
\hline Squamous cell carcinoma & 3 & 9 & 12 \\
\hline Large cell carcinoma & I & 4 & 5 \\
\hline \multicolumn{4}{|l|}{ Prior treatment (n) } \\
\hline No & 22 & 47 & 69 \\
\hline Yes & 7 & I & 8 \\
\hline Surgery & 6 & 1 & 7 \\
\hline Extrathoracic RT & 1 & 0 & 1 \\
\hline \multicolumn{4}{|l|}{ Stage (n) } \\
\hline IIIA & 4 & 2 & 6 \\
\hline$\| \mathrm{BB}$ & 4 & 12 & 16 \\
\hline IV & 21 & 34 & 55 \\
\hline
\end{tabular}

$n$, number of patients; $R T$, radiation therapy. 
Table 2 Adherence and dose limiting toxicities (DLTs)

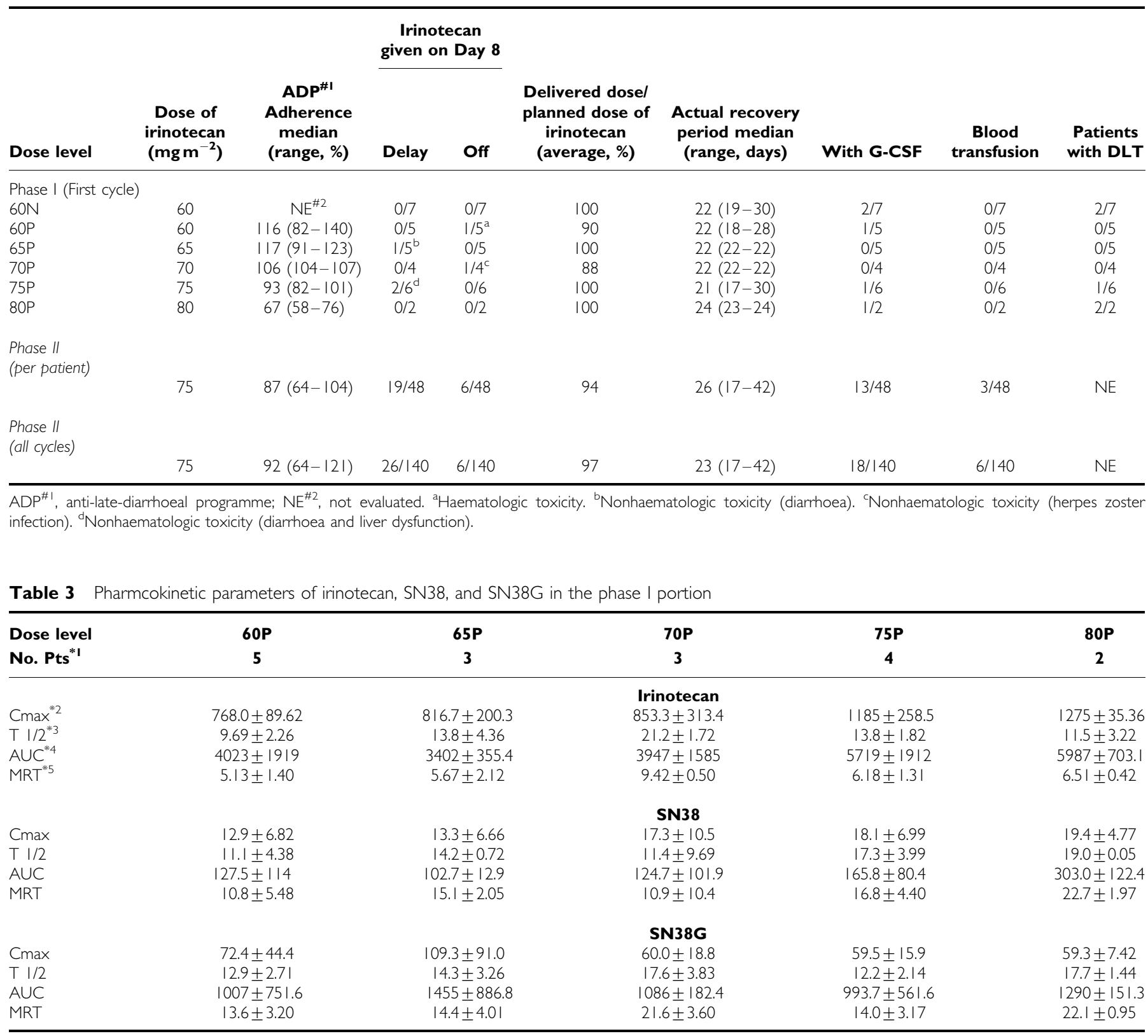

pts, patients; Cmax, maximun concentration $\left(n g \mathrm{ml}^{-1}\right) ; T_{1 / 2}$, elimination half-life $(h) ; A U C$, area under the curve $\left(n g \mathrm{ml}^{-1} \mathrm{~h}^{-1}\right)$; $M R T$, mean residence time $(h)$.

(25\%) exhibited Grade 3 toxicity (hyponatraemia for lasting 4 days, though it did not meet the definition of DLTs). At 75P, one of six patients (17\%) experienced a DLT (Grade 3 serum glutamic oxaloacetic and glutamic pyruvic transaminases for 8 days). Two patients were enrolled in level 80P, and both of them experienced DLTs; one patient had Grade 4 leucopenia with fever, Grade 4 diarrhoea and Grade 3 delusions, and the other had Grade 4 diarrhoea and Grade 4 neutropenia with fever. Two consecutive patients also had severe toxicities that met DLTs. Even if an additional four patients were enrolled into this level, more than and equal to one-third of the patients experienced DLTs. The safety committee recommended not continuing the entry of this level. Therefore, the $80 \mathrm{P}$ was defined as the MTD and 75P was decided as the recommended dose for phase II studies. The adherence on ADP was more than $90 \%$ in patients treated in cohorts $60 \mathrm{P}$ to $75 \mathrm{P}$, and all of the patients in those levels exhibited
Grade 2 or less late diarrhoea. At the 80P dose level, severe nausea impaired adherence with ADP. Irinotecan dose actually delivered is listed in Table 2. Two patients (7\%) could not be given irinotecan on Day 8 , and three patients $(10 \%)$ had its administration delayed by a few days. The median recovery period from side effects was 22 days (range, 17-30 days) in all patients enrolled onto the phase I portion of the study. G-CSF administration was required in $17 \%$ of the patients.

\section{Pharmacokinetics}

Pharmacokinetic studies were performed in 17 patients receiving the phase I portion from 60P to $80 \mathrm{P}$ (Table 3). The Cmax and AUC of both irinotecan and SN38 tend to increase in a dose-dependent manner (Figure 1). The correlations between the administrated dose of irinotecan and the Cmax of both irinotecan and SN38 are 

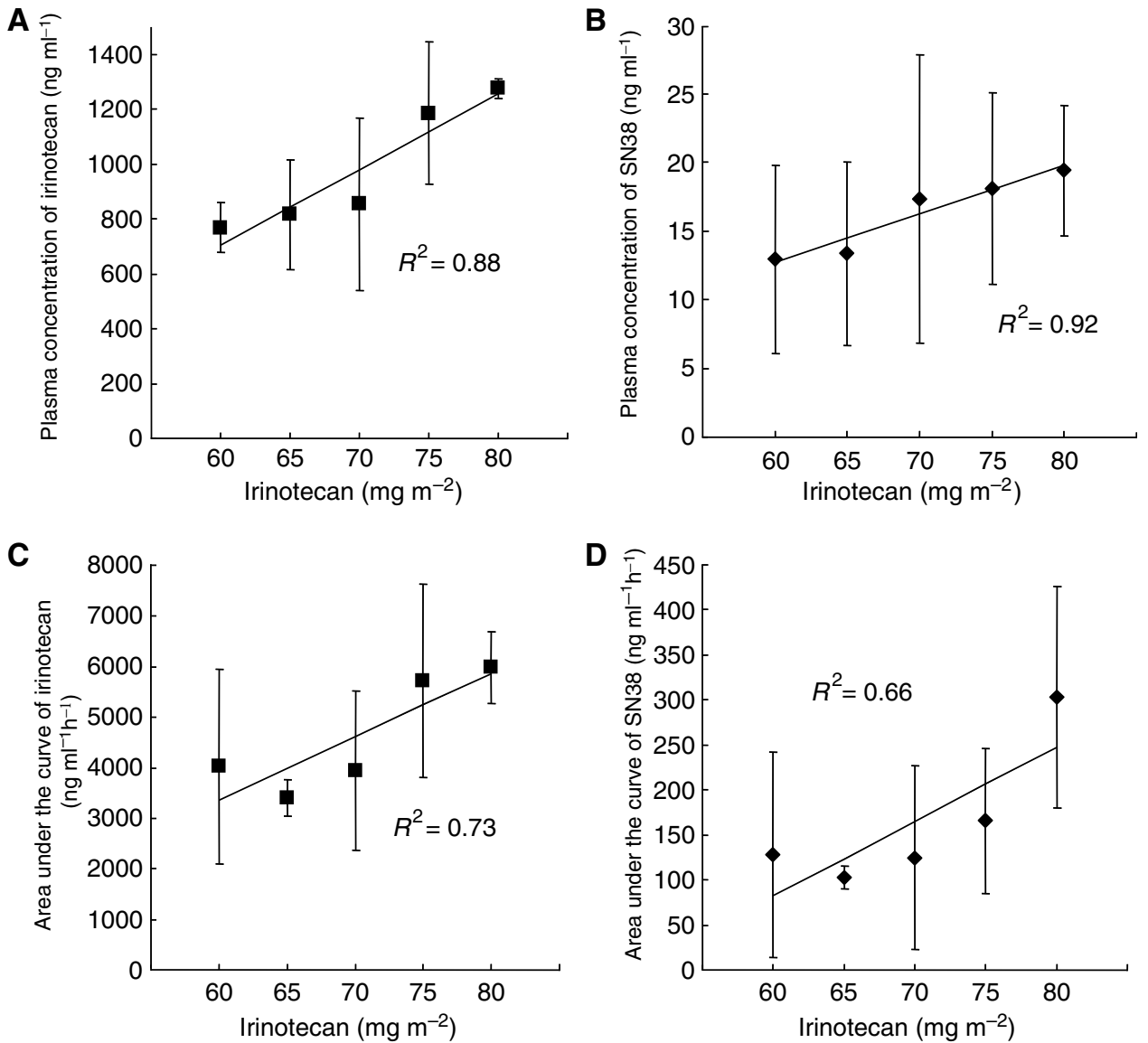

Figure I (A) Correlation between irinotecan dose $\left(\mathrm{mg} \mathrm{m}^{-2}\right)$ and maximum plasma concentration of irinotecan $\left(R^{2}=0.88, P=0.0\right.$ I 8$)$. $(\mathbf{B})$ Correlation between irinotecan dose $\left(\mathrm{mg} \mathrm{m}^{-2}\right)$ and maximum plasma concentration of SN38 $\left(R^{2}=0.92, P=0.0 \mathrm{I}\right)$. (C) Correlation between irinotecan dose (mg $\left.\mathrm{m}^{-2}\right)$ and $\mathrm{AUC}_{0 \text {-infinite }}$ of irinotecan $\left(R^{2}=0.73, P=0.067\right)$. (D) Correlation between irinotecan dose $\left(\mathrm{mg} \mathrm{m}^{-2}\right)$ and $\mathrm{AUC} \mathrm{C}_{0 \text {-infinite }}$ of $\mathrm{SN} 38\left(R^{2}=0.66, P=0.095\right)$.

also observed by simple regression models. However, no tendencies were observed in $T_{1 / 2}$ and MRT of irinotecan. There is no consistent tendency in $\mathrm{T}_{1 / 2}$ and MRT of SN38 and in all parameters of SN38G.

\section{Toxicities in Phase II}

In all, 48 patients and 140 cycles of chemotherapy (mean 3, range $1-5$ ) were given in the phase II portion of the study. Table 2 shows the adherence of the therapy, recovery period, and additional supportive procedures by patient and cycle. When we evaluated these factors by patient, the worst values during the treatment were shown. The median adherence with ADP was $87 \%$ per patient (Table 2). Reduction of the irinotecan dose was performed in only two patients. The Day 8 dose of irinotecan could not be administered in $13 \%$, whereas in 19 patients $(40 \%)$ it was delayed. The median recovery period from all side effects was 26 days (range, 17-42 days). The toxicity data by patient and cycle are described in Tables 4 and 5. The maximum toxicities during the treatment are shown in terms of the data by patient. Grade 2 or greater leucopenia occurred in 37 patients (77\%), with Grades 3 and 4 leucopenia occurring in 15 patients $(31 \%)$ and 1 patient $(2 \%)$, respectively (Table 4$)$. Neutropenia $\geqslant$ Grade 2 was observed in 42 patients $(88 \%)$, with Grades 3 and 4 neutropenia observed in $24(50 \%)$ and seven (15\%) patients, respectively. Febrile neutropenia, defined as Grade 3 or 4 neutropenia concomitant with $\geqslant$ Grade 2 fever, was observed in 11 patients $(23 \%)$. As a result, 13 patients $(27 \%)$ required G-CSF administration. Grade 3 or 4 anaemia was observed in nine patients (19\%), and three patients $(6 \%)$ required red blood cell transfusions. Grade 3 or greater thrombocytopenia was observed in only one patient. No patient required a platelet transfusion.

Gastrointestinal toxicity was the most prominent nonhaematological toxicity (Table 5). Nausea (>Grade 1) was the most common gastrointestinal toxicity, occurring in $65 \%$ of patients. According to the protocol, ADP was not discontinued if Grade 1 diarrhoea occurred. Since early diarrhoea included diarrhoea possibly related to ADP, the frequency of $>$ Grade 1 was $38 \%$. Only one patient had Grade 3 early diarrhoea, and she recovered from it when ADP was stopped. Furthermore, late diarrhoea $>$ Grade 1 was observed in $10(21 \%)$ patients. Grade 3 diarrhoea was observed in three patients $(6 \%)$, and no Grade 4 diarrhoea was observed. Other Grade 3 or 4 nonhaematological toxicities were as follows: fatigue (two patients), infection except febrile neutropenia (one patient), liver dysfunction (toxicities of bilirubin, four patients; toxicities of transaminases, six patients), and hyponatraemia (one patient). There was no severe pulmonary toxicity noted in this study.

In general, PS represents a common (albeit global) parameter of change (Cella et al, 1993). In the phase II portion, PS was serially checked during all cycles of the chemotherapy in each patient (Figure 2). The subtraction PS during chemotherapy by patient was calculated to subtract the worst PS during total cycles of chemotherapy from the PS at the start of chemotherapy. Two (4\%) had a -2 value of subtraction PS during chemotherapy and 15 (31\%) patients had a -1 value. Although $35 \%$ of patients had 
Table 4 Haematologic toxicities

Number of patients (cycles) with toxicity

\begin{tabular}{|c|c|c|c|c|c|c|c|c|c|c|c|c|c|}
\hline \multirow[b]{2}{*}{$\begin{array}{l}\text { Dose } \\
\text { level }\end{array}$} & \multirow[b]{2}{*}{$\begin{array}{c}\text { No. Pts } \\
\text { (cycles) }\end{array}$} & \multicolumn{4}{|c|}{ Leukopenia } & \multicolumn{4}{|c|}{ Neutropenia } & \multicolumn{2}{|c|}{ Anemia } & \multicolumn{2}{|c|}{ Thrombocytopenia } \\
\hline & & $\begin{array}{l}\text { Mean nadir } \\
\text { (Range: } \mu^{-1} \text { ) }\end{array}$ & $\begin{array}{c}\text { Grade } \\
2\end{array}$ & $\begin{array}{c}\text { Grade } \\
3\end{array}$ & $\begin{array}{c}\text { Grade } \\
4\end{array}$ & $\begin{array}{l}\text { Mean nadir } \\
\left(\text { Range: } \mu I^{-1}\right)\end{array}$ & $\begin{array}{c}\text { Grade } \\
2\end{array}$ & $\begin{array}{c}\text { Grade } \\
3\end{array}$ & $\begin{array}{c}\text { Grade } \\
\quad 4\end{array}$ & $\begin{array}{l}\text { Mean nadir } \\
\text { (Range: } \\
\left.\text { gdl }^{-1}\right)\end{array}$ & $\begin{array}{c}\text { Grade } \\
3-4\end{array}$ & $\begin{array}{l}\text { Mean nadir } \\
\text { (Range: } \\
\left.\times\left. 10^{4} \mu\right|^{-1}\right)\end{array}$ & $\begin{array}{c}\text { Grade } \\
3-4\end{array}$ \\
\hline \multicolumn{14}{|l|}{ Phase I } \\
\hline $60 \mathrm{~N}$ & $7(13)$ & $2806(1000-4160)$ & $3(5)$ & $3(3)$ & 0 & $1276(324-2288)$ & $2(5)$ & I (2) & $2(2)$ & $10.7(8.0-12.7)$ & 0 & $18.3(11.3-25.1)$ & 0 \\
\hline $60 \mathrm{P}$ & $5(8)$ & $2123(1300-3560)$ & $3(4)$ & I (3) & 0 & $877(312-1940)$ & $1(1)$ & $2(5)$ & $1(1)$ & $9.8(8.7-13.3)$ & 0 & $\mid 4.8(8.0-18.8)$ & 0 \\
\hline $75 P$ & $6(15)$ & $2825(1800-4080)$ & $4(9)$ & I (I) & 0 & $1303(378-2489)$ & $3(4)$ & $2(5)$ & I (I) & $9.8(8.0-12.1)$ & 0 & $20.6(8.7-33.6)$ & 0 \\
\hline $80 \mathrm{P}$ & $2(2)$ & $1235(400-2070)$ & I (I) & 0 & I (I) & $446(200-691)$ & 0 & I (I) & I ( I) & $11.7(10.8-12.5)$ & 0 & $12.6(9.4-15.8)$ & 0 \\
\hline Phase II & $48(140)$ & $2926(510-7290)$ & $21(64)$ & $15(22)$ & I (2) & $1303(112-36 / 2)$ & II (49) & $24(42)$ & $7(10)$ & $9.8(5.7-13.6)$ & $9(14)$ & $19.2(4.9-45.5)$ & I (I) \\
\hline
\end{tabular}

${ }^{a}$ Number of patients (cycles).

Table 5 Nonhaematologic toxicities

\begin{tabular}{|c|c|c|c|c|c|c|c|}
\hline \multirow{3}{*}{$\begin{array}{l}\text { Dose level } \\
\text { Number of } \\
\text { patients (cycles) }\end{array}$} & \multicolumn{6}{|c|}{ Phase I } & \multirow[b]{2}{*}{ Phase II } \\
\hline & $60 N$ & $60 P$ & $65 P$ & 70P & $75 P$ & $80 \mathrm{P}$ & \\
\hline & 7 (13) & $5(8)$ & $5(14)$ & $4(9)$ & $6(15)$ & $2(2)$ & $48(140)$ \\
\hline \multicolumn{8}{|l|}{ Fatigue } \\
\hline Grade 2 & 0 & I (I) & I (I) & 0 & 0 & 0 & $12(16)$ \\
\hline Grade 3 & 0 & 0 & 0 & 0 & 0 & $2(2)$ & $2(2)$ \\
\hline Grade 4 & 0 & 0 & 0 & 0 & 0 & 0 & 0 \\
\hline \multicolumn{8}{|l|}{ Nausea } \\
\hline Grade 2 & $5(8)$ & $3(3)$ & $3(6)$ & $3(5)$ & $5(10)$ & 0 & $24(40)$ \\
\hline Grade 3 & 0 & $1(1)$ & 0 & $1(1)$ & 0 & $2(2)$ & $7(10)$ \\
\hline Grade 4 & 0 & 0 & 0 & 0 & 0 & 0 & 0 \\
\hline \multicolumn{8}{|l|}{ Infection } \\
\hline Grade 2 & I (I) & 0 & I (2) & $2(2)$ & I (I) & 0 & $9(14)$ \\
\hline Grade 3 & I (I) & 0 & 0 & 0 & 0 & 0 & I (I) \\
\hline Grade 4 & 0 & 0 & 0 & 0 & 0 & 0 & 0 \\
\hline$+N P G^{a} \geqslant 3$ & I (I) & 0 & 0 & 0 & I (I) & $2(2)$ & $11(13)$ \\
\hline \multicolumn{8}{|l|}{ Early diarrhoea } \\
\hline Grade 2 & I (I) & I (2) & I (I) & I (I) & $3(4)$ & 0 & $17(23)$ \\
\hline Grade 3 & 0 & 0 & 0 & 0 & 0 & I (I) & I (I) \\
\hline Grade 4 & 0 & 0 & 0 & 0 & 0 & 0 & 0 \\
\hline \multicolumn{8}{|l|}{ Late diarrhoea } \\
\hline Grade 2 & $2(2)$ & $2(2)$ & $2(3)$ & I (I) & $2(3)$ & 0 & $7(9)$ \\
\hline Grade 3 & 0 & 0 & 0 & 0 & 0 & 0 & $3(3)$ \\
\hline Grade 4 & 0 & 0 & 0 & 0 & 0 & $2(2)$ & 0 \\
\hline \multicolumn{8}{|l|}{ Total bilirubin } \\
\hline Grade 2 & I (I) & 0 & I (2) & I (3) & I (I) & $2(2)$ & $7(13)$ \\
\hline Grade 3 & 0 & 0 & 0 & $1(1)$ & 0 & 0 & $4(4)$ \\
\hline Grade 4 & 0 & 0 & 0 & 0 & 0 & 0 & 0 \\
\hline \multicolumn{8}{|l|}{ Transaminases } \\
\hline Grade 2 & 0 & 0 & 0 & 0 & 0 & 0 & $3(5)$ \\
\hline Grade 3 & 0 & 0 & 0 & 0 & I (2) & 0 & $3(6)$ \\
\hline Grade 4 & 0 & 0 & 0 & 0 & 0 & 0 & 0 \\
\hline \multicolumn{8}{|l|}{ Hyponatremia } \\
\hline Grade 2 & $2(3)$ & 0 & 0 & 0 & $2(2)$ & 0 & || (|7) \\
\hline Grade 3 & I (I) & 0 & 0 & I (I) & 0 & I (I) & I (I) \\
\hline Grade 4 & 0 & 0 & 0 & 0 & 0 & 0 & 0 \\
\hline
\end{tabular}

a Neutropenia grade.

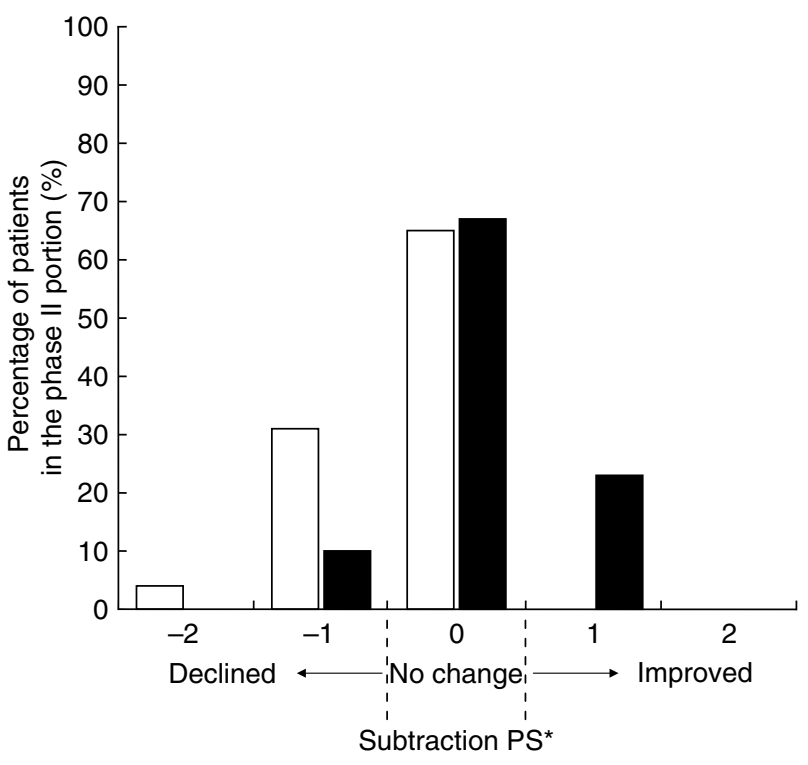

Figure 2 Change of performance status (PS) in each patient. *; Subtraction PS is to subtract the PS at particular time points during chemotherapy from the PS at the start of the chemotherapy. Plus value of subtraction PS means improved PS. Minus value of subtraction PS means declined PS. Open bars represent subtraction PS during chemotherapy, which is to subtract the worst PS during total cycles in each patient from the PS at the start of chemotherapy. Solid bars represent subtraction PS at the end of the chemotherapy, which is to subtract the PS at the end of the treatment from the PS at the start of chemotherapy

declined PS, $65 \%$ of patients had no change in PS during this treatment. The subtraction PS at the end was to subtract the PS at the end of this regimen from the PS at the start of chemotherapy. Five $(10 \%)$ patients had a -1 value of subtraction PS at the end. In all, $11(23 \%)$ patients had a +1 value. At the end of the chemotherapy, $23 \%$ of patients had improved PS and $67 \%$ of patients had no change in PS.

\section{Efficacy}

A total of 27 patients were evaluable for response in the phase I portion of the study and all 48 of the patients in the phase II portion (Table 6). In the phase II portion of the study, the response 


\begin{tabular}{|c|c|c|c|c|c|c|c|}
\hline \multirow[b]{2}{*}{ Group } & \multirow[b]{2}{*}{ No. of evaluable patients } & \multirow{2}{*}{$\begin{array}{c}\text { CR } \\
\text { No. }\end{array}$} & \multirow{2}{*}{$\begin{array}{c}\text { PR } \\
\text { No. }\end{array}$} & \multicolumn{2}{|c|}{ CR+PR } & \multicolumn{2}{|c|}{ PD } \\
\hline & & & & No. & $\%$ & No. & $\%$ \\
\hline \multicolumn{8}{|l|}{ Phase I } \\
\hline $60 \mathrm{~N}$ & 7 & 0 & । & I & 14.3 & 2 & 28.6 \\
\hline $60 P$ & 5 & 0 & I & I & 20.0 & 2 & 40.0 \\
\hline $65 \mathrm{P}$ & 4 & 0 & 3 & 3 & 75.0 & 0 & 0 \\
\hline $70 P$ & 3 & 0 & 0 & 0 & 0 & । & 33.3 \\
\hline $75 P$ & 6 & । & 3 & 4 & 66.0 & 0 & 0 \\
\hline $80 \mathrm{P}$ & 2 & 0 & । & 1 & 50 & 0 & 0 \\
\hline Phase II & 48 & 0 & 30 & 30 & $62.5(47.3-76.0)^{\mathrm{a}}$ & 7 & $\mid 4.6(6 . \mid-27.8)$ \\
\hline Total & 75 & I & 39 & 40 & $53.3(41.4-64.9)$ & 12 & $16.0(8.5-26.3)$ \\
\hline
\end{tabular}

CR, complete response; PR, partial response; PD, progressive disease defined by WHO response criteria. ${ }^{a} 95 \%$ confidential interval.
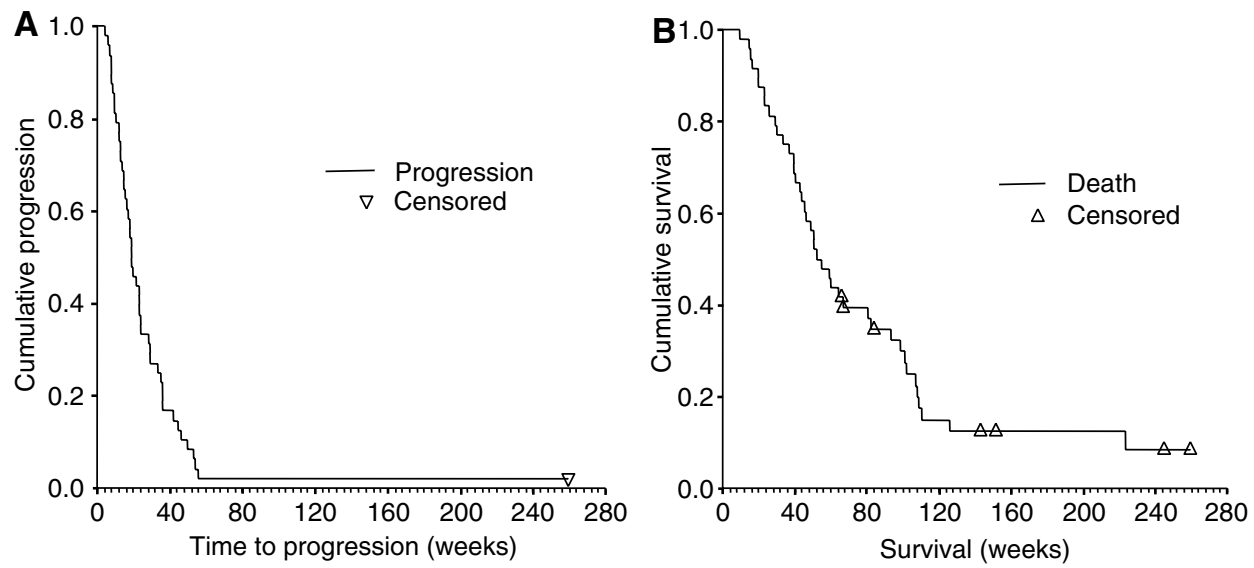

Figure 3 Time to progression and survival of 48 patients enrolled in phase II. (A) Time to progression of patients in phase II. (B) Survival of patients in phase II.

rate was $63 \%$ (95\% confidential interval (CI), $47-76 \%$ ) by intent to treat analysis. Among these 75 evaluable patients, one patient had a complete response, 39 patients had a partial response, 23 patients had stable disease, and 12 patients had progressive disease. The overall response rate was 53\% (95\% CI, $41-65 \%)$.

As of November 2003, median follow-up was 56 months $(95 \%$ CI, 17-95 months). All other patients, except one patient in the phase I portion of this study, were followed up. Median TTP was 19 weeks (95\% CI, 14-25 weeks). Survival rates (1 and 2 years) were $59 \%$ (95\% CI, $46-71 \%)$ and $23 \%(95 \%$ CI, $13-35 \%)$, respectively. Median survival was 56 weeks (95\% CI, 42-70 weeks).

For the 48 patients in phase II (Figure 3), median TTP was 19 weeks (95\% CI, 15-22 weeks, Figure 3a). One-year and two-year survival rates for the patients in phase II were 50\% (95\% CI, 35$65 \%)$ and $21 \%(95 \% \mathrm{CI}, 10-35 \%)$, respectively. Median survival was 52 weeks (95\% CI, 39-64 weeks, Figure 3b).

\section{DISCUSSION}

Although the DLTs of single agent irinotecan include leucopenia and neutropenia, the principal toxicity is late diarrhoea. Its irinotecan-induced late diarrhoea appears unexpectedly and is unpredictable. We conducted a phase I/II study of irinotecan and cisplatin with the addition of ADP to decrease late diarrhoea. The first dose level of $60 \mathrm{~N}$ is almost the same as the standard regimen used in Japan (Noda et al, 2002). The standard regimen of this combination chemotherapy consists of $60 \mathrm{mg} \mathrm{m}^{-2}$ cisplatin on Day 1 and $60 \mathrm{mg} \mathrm{m}^{-2}$ irinotecan on Days 1,8 , and 15 , every 4 weeks. Grade 3 or 4 late diarrhoea occurred in $16 \%$ of their patients treated with cisplatin plus irinotecan and in none of their patients treated with cisplatin plus etoposide. We chose to study cisplatin in combination with irinotecan for the following reasons: (1) platinum-based chemotherapy is standard first-line treatment for advanced NSCLC; (2) the combination of cisplatin and irinotecan is associated with a high incidence of late diarrhoea. (3) Toxicity limited the delivery of the planned dose of irinotecan dose to less than $59 \%$ of cycles (Masuda et al, 1998). The ability to deliver the planned doses of irinotecan should lead to improvement of the efficacy of this combination regimen. In our study, $97 \%$ of the planned dose irinotecan dose by cycle was actually administered (Table 2). We hypothesised that incorporation of ADP would improve the delivery of the planned dose of irinotecan dose by decreasing side effects although we were aware of the possibility that altered metabolic clearance of irinotecan could result in reduced efficacy (Mathijssen et al, 2001). Even if this were the case, ADP could increase the actual usage of irinotecan. When the administration dose of irinotecan was increased by use of ADP, the AUC and the Cmax of irinotecan also increased (Figure 1). The results of our pharmacokinetic study show that the AUC and the Cmax of both irinotecan and SN38 tend to increase in the dose-dependent manner of irinotecan. Related to this phase I/II study, we also conducted another pharmacokinetic study to compare PK parameters with or without ADP. The analysis is ongoing using the noncompartment model. This preliminary data is showing that MRT of irinotecan and $T_{1 / 2}$ of SN38 in high adherence of ADP were shorter than those in its low adherence. We supposed that the dose escalation of irinotecan could be performed by increasing the elimination of these two compounds. 
There is one report in a phase II study of irinotecan and cisplatin without ADP, that grade 3 or 4 leucopenia, neutropenia, and late diarrhoea occurred in 32 (46\%), $53(80 \%)$, and 13 (19\%), respectively, of 69 patients (Masuda et al, 1998). In the phase II portion of our study, grade 3 or 4 leucopenia, neutropenia, and late diarrhoea occurred in 33,65 , and $6 \%$ of patients, respectively (Tables 4 and 5). Even though their dose schedule was slightly different from ours, all of their major toxic effects are lower in our study than those in the above study. When we examined toxicities profile by cycle, grade 3 or 4 leucopenia, neutropenia, and late diarrhoea occurred in 17,37 , and $2 \%$ of cycles, respectively (Tables 4 and 5). A common parameter of change is PS and it was predicted that the physical and functional factor would show the most significant sensitivity to change in PS (Cella et al, 1993). In case of FACT-G, change in PS was related to physical, functional, and emotional factors but not to the social or relational situation with the doctor. In the EORTC QLQ-C30, the same relationship was observed (Aaronson et al, 1993). Hence, PS was serially checked during all cycles of this treatment by patients. Although $35 \%$ of patients temporally had declined PS probably due to the side effects, the PS did not change in $65 \%$ of patients during this treatment (Figure 2). At the end of the chemotherapy, PS had not declined in $90 \%$ of patients. These changes of PS might be feasible for patients who received the cisplatin-based doublet chemotherapy (Aaronson et al, 1993).

The response rate in our study was $63 \%$ in the phase II portion. Median TTP was 19 weeks and median survival 52 weeks. When we reviewed the patients enrolled in this study, there were two patients with stage IIIA disease in the phase II portion. However, in order to maintain the statistical power of this study, these two patients could not be removed from the efficacy profile. In order to compare the efficacy profiles with the other study, we also analysed the data of 46 patients with IIIB/IV. The response rate, median TTP, and median survival in them were $61 \%$ (95\% CI, $45-75 \%), 18$ weeks (95\% CI, 15-21 weeks), and 52 weeks (95\% CI, 40-65 weeks), respectively. There was a probability that these efficacy profiles might be better than those previously reported with other platinum-based combination regimens in phase II studies (Berthaud et al, 1992; Johnson et al, 1996; von Pawel et al, 1996; Masuda et al, 1998; Zalcberg et al, 1998; Bretti et al, 2002).

After this combination chemotherapy, 33 (69\%) of 48 patients in our phase II were given second-line chemotherapies. Only 5 (10\%) patients were treated by docetaxel (Shepherd et al, 2000). When these 5 patients were excluded, the median survival of 43 patients was 54 weeks ( $95 \%$ CI, 38-71 weeks). These data suggest that second-line chemotherapy by docetaxel might not influence the survival of patients in our study.

In conclusion, irinotecan and cisplatin can be made more tolerable with ADP. The irinotecan and cisplatin with ADP resulted in promising efficacy with acceptable toxicity. In order to prove the efficacy of this regimen, a randomised phase III trial is necessary.

\section{ACKNOWLEDGEMENTS}

We also thank Drs Suresh Ramalingam and Merrill J Egorin for helpful discussions and criticisms of this manuscript.

\section{REFERENCES}

Aaronson NK, Ahmedzai S, Bergman B, Bullinger M, Cull A, Duez NJ, Filiberti A, Flechtner H, Fleishman SB, de Haes JCJM, Kaasa S, Klee M, Osoba D, Razavi D, Rofe PB, Schraub S, Sneeuw K, Sullivan M, Takeda F, the European Organization for Research and Treatment of Cancer Study Group on Quality of Life (1993) The European Organization for Research and Treatment of Cancer QLQ-C30: a quality-of-life instrument for use in international clinical trials in oncology. J Natl Cancer Inst 85: 365-376

Berthaud P, Le Chevalier T, Ruffie P, Baldeyrou P, Arriagada R, Besson F, Tursz T (1992) Phase I-II study of vinorelbine (Navelbine) plus cisplatin in advanced non-small cell lung cancer. Eur J Cancer 28A: $1863-1865$

Bleiberg H, Cvitkovic E (1996) Characterisation and clinical management of CPT-11 (irinotecan)-induced adverse events: the European perspective. Eur J Cancer 32A(Suppl 3): S18-S23

Bretti S, Manzin E, Loddo C, Berruti A, Bombaci S, Vellani G, Celano A (2002) Gemcitabine plus cisplatin in the treatment of patients with advanced non-small cell lung cancer: a phase II study. Anticancer Res 22: $3039-3043$

Cella DF, Tulsky DS, Gray G, Sarafian B, Linn E, Bonomi A, Silberman M, Yellen SB, Winicour P, Brannon J, Eckberg K, Lloyd S, Purl S, Blendowski C, Goodman M, Barnicle M, Stewart I, McHale M, Bonomi P, Kaplan E, Taylor IV S, Thomas Jr R, Harris J (1993) The functional assessment of cancer therapy scale: development and validation of the general measure. J Clin Oncol 11: 570-579

Conti JA, Kemeny NE, Saltz LB, Huang Y, Tong WP, Chou TC, Sun M, Pulliam S, Gonzalez C (1996) Irinotecan is an active agent in untreated patients with metastatic colorectal cancer. J Clin Oncol 14: 709-715

Fukuoka M, Niitani H, Suzuki A, Motomiya M, Hasegawa K, Nishiwaki Y, Kuriyama T, Ariyoshi Y, Negoro S, Masuda N, Nakajima S, Taguchi T (1992) A phase II study of CPT-11, a new derivative of camptothecin, for previously untreated non-small-cell lung cancer. J Clin Oncol 10: 16-20

Gandia D, Abigerges D, Armand JP, Chabot G, Da Costa L, De Forni M, Mathieu-Boue A, Herait P (1993) CPT-11-induced cholinergic effects in cancer patients. J Clin Oncol 11: 196-197

Garcia-Carbonero R, Supko JG (2002) Current perspectives on the clinical experience, pharmacology, and continued development of the camptothecins. Clin Cancer Res 8: $641-661$
Ikegami T, Ha L, Arimori K, Latham P, Kobayashi K, Ceryak S, Matsuzaki Y, Bouscarel B (2002) Intestinal alkalization as a possible preventive mechanism in irinotecan (CPT-11)-induced diarrhea. Cancer Res 62: $179-187$

Johnson DH, Paul DM, Hande KR, Shyr Y, Blanke C, Murphy B, Lewis M, De Vore III RF (1996) Paclitaxel plus carboplatin in advanced non-smallcell lung cancer: a phase II trial. J Clin Oncol 14: 2054-2060

Kaplan E, Meier P (1958) Nonparametric estimation from incomplete observation. J Am Stat Assoc 53: 457-481

Kobayashi K, Bouscarel B, Matsuzaki Y, Ceryak S, Kudoh S, Fromm H (1999) $\mathrm{pH}$-dependent uptake of irinotecan and its active metabolite, SN-38, by intestinal cells. Int J Cancer 83: $491-496$

Kobayashi K, Shinbara A, Kamimura M, Takeda Y, Kudo K, Kabe J, Hibino S, Hino M, Shibuya M, Kudoh S (1998) Irinotecan (CPT-11) in combination with weekly administration of cisplatin (CDDP) for nonsmall-cell lung cancer. Cancer Chemother Pharmacol 42: 53-58

Kurita A, Kaneda N (1999) High-performance liquid chromatographic method for the simultaneous determination of the camptothecin derivative irinotecan hydrochloride, CPT-11, and its metabolites SN-38 and $\mathrm{SN}-38$ glucuronide in rat plasma with a fully automated on-line solid-phase extraction system, PROSPEKT. J Chromatogr B Biomed Sci Appl 724: 335 - 344

Masuda N, Fukuoka M, Fujita A, Kurita Y, Tsuchiya S, Nagao K, Negoro S, Nishikawa H, Katakami N, Nakagawa K, Niitani H (1998) A phase II trial of combination of CPT-11 and cisplatin for advanced non-small-cell lung cancer. Br J Cancer 78: $251-256$

Mathijssen RHJ, van Alphen RJ, Verweij J, Loos WJ, Nooter K, Stoter G, Sparreboom A (2001) Clinical pharmacokinetics and metabolism of irinotecan (CPT-11). Clin Cancer Res 7: 2182-2194

Merrouche Y, Extra JM, Abigerges D, Bugat R, Catimel G, Suc E, Marty M, Herait P, Mahjoubi M, Armand JP (1997) High dose-intensity of irinotecan administered every 3 weeks in advanced cancer patients: a feasibility study. J Clin Oncol 15: 1080-1086

Noda K, Nishiwaki Y, Kawahara M, Negoro S, Sugiura T, Yokoyama A, Fukuoka M, Mori K, Watanabe K, Tamura T, Yamamoto S, Saijo N, Japan Clinical Oncology Group (2002) Irinotecan plus cisplatin 
compared with etoposide plus cisplatin for extensive small-cell lung cancer. $N$ Engl J Med 346: 85-91

Non-small Cell Lung Cancer Collaborative Group (1995) Chemotherapy in non-small cell lung cancer: a meta-analysis using updated data on individual patients from 52 randomised clinical trials. BMJ 311: 899-909

Saltz LB, Cox JV, Blanke C, Rosen LS, Fehrenbacher L, Moore MJ, Maroun JA, Ackland SP, Locker PK, Pirotta N, Elfring GL, Miller LL (2000) Irinotecan plus fluorouracil and leucovorin for metastatic colorectal cancer. Irinotecan Study Group. N Engl J Med 343: $905-914$

Schemper M, Smith TL (1996) A note on quantifying follow-up in studies of failure time. Control Clin Trials 17: $343-346$

Schiller JH, Harrington D, Belani CP, Langer C, Sandler A, Krook J, Zhu J, Johnson DH, Eastern Cooperative Oncology Group (2002) Comparison of four chemotherapy regimens for advanced non-small-cell lung cancer. $N$ Engl J Med 346: $92-98$

Shepherd FA, Dancey J, Ramlau R, Mattson K, Gralla R, O’Rourke M, Levitan N, Gressot L, Vincent M, Burkes R, Coughlin S, Kim Y, Berille J (2000) Prospective randomized trial of docetaxel versus best supportive care in patients with non-small-cell lung cancer previously treated with platinum-based chemotherapy. J Clin Oncol 18: 2095-2103

Simon R (1989) Optimal two-stage designs for phase II clinical trials. Control Clin Trials 10: $1-10$

Strazzabosco M, Sakisaka S, Hayakawa T, Boyer JL (1991) Effect of UDCA on intracellular and biliary $\mathrm{pH}$ in isolated rate hepatocyte couplets and perfused livers. Am J Physiol 109: 260:G58-69

Takeda Y, Kobayashi K, Akiyama Y, Soma T, Handa S, Kudoh S, Kudo K (2001) Prevention of irinotecan (CPT-11)-induced diarrhea by oral alkalization combined with control of defecation in cancer patients. Int $J$ Cancer 92: 269-275

von Pawel J, Wagner H, Niederle N, Heider A, Koschel G, Hecker D, Hanske M (1996) Phase II study of paclitaxel and cisplatin in patients with nonsmall cell lung cancer. Semin Oncol 23(Suppl 16): $47-50$

Zalcberg J, Millward M, Bishop J, McKeage M, Zimet A, Toner G, Friedlander M, Barter C, Rischin D, Loret C, James R, Bougon N, Berille J (1998) Phase II study of docetaxel and cisplatin in advanced non-smallcell lung cancer. J Clin Oncol 16: 1948-1953 